\title{
O Plano de Desenvolvimento do Lago de Furnas de 1975: o desafio da integração regional
}

\author{
The Development Plan of Furnas Lake of 1975: the challenge of regional \\ integration
Le Plan de Développement du Lac Furnas de 1975: le défi de l'intégration régionale
El Plan de Desarrollo del Lago de Furnas 1975: el desafío de la integración regional

\author{
Carlos Eduardo Pozzer ${ }^{1}$ \\ André Munhoz de Argollo Ferrão² \\ Recebido em 15/08/2017; revisado e aprovado em 22/11/2017; aceito em 20/12/2017 \\ DOI: http://dx.doi.org/10.20435/inter.v19i4.1688
}

\begin{abstract}
Resumo: Este artigo estabelece uma reflexão sobre o Plano de Desenvolvimento do Lago de Furnas de 1975. O plano é analisado como uma estratégia de planejamento regional voltado ao enfrentamento dos impactos socioambientais causados pelo processo de implantação do Lago de Furnas nos municípios. As principais propostas do plano são destacadas e posteriormente são analisados os seus desdobramentos no contexto atual do território do entorno do Lago de Furnas.
\end{abstract}

Palavras-chave: Lago de Furnas; Tennessee Valley Authority; Minas Gerais.

Abstract: This paper establishes a thinking about the Development Plan of Furnas Lake of 1975. The plan is analyzed as a regional planning strategy that sought to confront the social and environmental impacts caused by the process of implantation of Furnas Lake in the cities. The main proposals of the plan are highlighted and later are analyzed its influences in the current context of the territory around the Lake of Furnas.

Keywords: Furnas Lake; Tennessee Valley Authority; Minas Gerais.

Résumé: Ce article établit une réflexion sur l'expérience de élaboration du plan de développement du lac Furnas 1975. Le plan est considéré comme une stratégie de planification régionale qui a cherché à répondre aux impacts socio-économiques et environnementaux dans leurs cités avec la mise en œuvre de Lac Furnas. Les principales propositions du plan sont identifiées et sont vérifiées leurs influences dans le contexte actuel entourant le lac du territoire Furnas.

Mots-clés: Lac Furnas; Tennessee Valley Authority; Minas Gerais.

Resumen: Este artículo establece una reflexión sobre el Plan de Desarrollo del Lago de Furnas de 1975. El plan es analizado como una estrategia de planificación regional orientada al enfrentamiento de los impactos socioambientales causados por el proceso de implantación del Lago de Furnas en las ciudades. Las principales propuestas del plan son destacadas y posteriormente se analizan sus influencias en el contexto actual del territorio del entorno del Lago de Furnas.

Palabras-clave: Lago de Furnas; Tennessee Valley Authority; Minas Gerais.

\section{INTRODUÇÃO}

O urbanismo, definido como disciplina crítica e reflexiva, nasceu a partir do enfrentamento dos problemas das cidades que foram transformadas pela Revolução Industrial. As cidades industriais europeias do século XIX desordenadas, superpopulosas, insalubres, carentes de soluções habitacionais e de circulação passaram a ser objeto de estudos, teorias, modelos e utopias que preconizaram a possibilidade do planejamento daqueles caóticos contextos urbanos (CHOAY, 1979).

\footnotetext{
1 Pontifícia Universidade Católica de Minas Gerais, Poços de Caldas, Minas Gerais, Brasil.

2 Universidade Estadual de Campinas, Campinas, São Paulo, Brasil.
} 
Curiosamente, a maior parte dessa produção teórica procurou enfrentar os problemas das grandes cidades, ou seja, poucas abordagens ampliaram essa reflexão para uma região ou para um conjunto de cidades. O foco na metrópole, enquanto questão estrutural, não permitiu uma reflexão mais profunda sobre a problemática das pequenas cidades isoladas e seus territórios, seus recursos ambientais e suas possiblidades de desenvolvimento.

Ebenezer Howard, na sua teoria das 'Cidades Jardins', desenvolveu a ideia do planejamento ou da gestão cooperativa de um sistema de pequenas cidades. As ideias de Howard foram publicadas em 1898, no livro Tomorrow: a Peaceful Path to Real Reform e, posteriormente, como Garden Cities of Tomorrow, em 1902, traduzido para o português como Cidades Jardins do Amanhã.

A 'Cidade Jardim' de Howard objetivava a superação da contradição campo/cidade, tal proposta foi representada no seu famoso diagrama dos três ímãs. Howard desenvolveu uma reflexão sobre o poder de atração do "Ímã Campo" e do "Ímã Cidade" concebendo um novo elemento de atração: o "Ímã Cidade-Campo", ou seja, a 'Cidade Jardim'.

Para Howard, a solução seria a recondução do homem ao campo com a criação de atrativos que pudessem compensar as vantagens da cidade. Já a 'Cidade-Campo', ou 'Cidade Jardim', integraria as qualidades da cidade e do campo num mesmo território (HOWARD, 1996).

Mais tarde, Patrick Geddes, estabeleceu uma relevante contribuição para essa reflexão concebendo as bases teóricas para o planejamento regional. Trabalhando com o conceito de região natural, que compreendia os recursos ambientais e as intervenções humanas em um mesmo ambiente, Geddes se distanciou do estudo da metrópole dirigindo-se para uma reflexão específica sobre a região (HALL, 2005).

Geddes apontava para a necessidade de um estudo panorâmico da região geográfica, considerando os rios e a bacia hidrográfica elementos fundamentais para o estudo das cidades. Afirmava que o planejamento regional deveria iniciar-se com os levantamentos dos recursos da região natural estudada, identificando as respostas do homem e a complexidade da paisagem cultural. Nesse contexto, o estudo das bacias hidrográficas se apresentava como uma tarefa fundamental para o planejamento regional (GEDDES, 1904 ).

Mais tarde, em 1923, as reflexões sobre o planejamento regional foram incrementadas com a criação nos Estados Unidos da América, da Regional Planning Association of America (RPAA), cujos membros desenvolveram um conjunto de planos e projetos procurando experimentar na América os ensinamentos de Howard e Geddes. Entre esses trabalhos, a RPAA desenvolveu estudos sobre a implantação regional de 'Cidades Jardins', estabelecendo, ao mesmo tempo, relações teóricas com planejadores britânicos, entre os quais Patrick Geddes. Os principais projetos da RPAA estavam relacionados com os planos regionais da Trilha Apalachiana e com o Vale do Tennessee (HALL, 2005).

Em 1933, com a eleição de Franklin Delano Roosevelt, foi implantada, nos Estados Unidos da América, uma série de programas e projetos que tinham como objetivo o enfrentamento da grande depressão que o país vivia desde 1929. Essa política, que recebeu o nome de New Deal, compreendeu um conjunto de programas e ações: grandes investimentos em obras públicas, eliminação dos estoques agrícolas, controle dos preços e a diminuição da jornada de trabalho. Nesse processo, foram criadas várias agências federais de desenvolvimento, entre as quais merece destaque, especialmente, a experiência da criação da Tennessee Valley Authority (TVA), que promoveu uma proposta de planejamento regional para o Vale do Tennessee, com a implantação de um conjunto de barragens, usinas hidrelétricas e sistemas de irrigação que viabilizaram o desenvolvimento daquela região (ALLEN, 1968). 
Roosevelt, alinhado com as teorias da RPAA, incentivou a volta das populações para o campo, oferecendo habitações e glebas rurais. Acreditava-se que os transportes rodoviários de carga e a energia elétrica possibilitariam a descentralização da indústria em direção às pequenas comunidades rurais. Nesse contexto, a TVA seria para Roosevelt uma estratégia de enfrentamento dos graves problemas socioeconômicos vividos pela população do Vale do Tennessee, naquele período (HALL, 2005).

Ao longo de sua história, a TVA desenvolveu consultorias internacionais nas áreas de produção de energia hidrelétrica, planejamento e gestão de recursos hídricos e planejamento regional. No Brasil, a criação da Companhia de Desenvolvimento do Vale do São Francisco (CODEVASF), em 1948, foi fortemente influenciada pela TVA (CAMPOLINA, 2014).

Já em 1975, Aelred J. Gray, membro do corpo técnico da TVA, foi contratado pelo Governo de Minas Gerais para a coordenação do Plano de Desenvolvimento do Lago de Furnas (PDLF), sendo esta a primeira proposta de planejamento regional para aquele território, objetivando enfrentar os impactos socioeconômicos, ambientais e culturais causados pela implantação do Lago de Furnas.

Este trabalho tem como objetivo identificar as principais diretrizes, previstas pelo PDFL em 1975, para o território do entorno do Lago de Furnas. Considerando que o conteúdo do PDFL é desconhecido pelos gestores e pela comunidade regional, o resgate dessas referidas diretrizes pode estabelecer uma importante contribuição para a compreensão e para o planejamento deste território. O PDFL deve ser entendido como um importante instrumento de planejamento regional, fortemente influenciado pelas experiências da TVA, o qual abordou o vasto território do entorno do Lago de Furnas e suas cidades. Sendo assim, o PDFL deve ser considerado como um documento histórico, que registra uma importante experiência da TVA no Brasil, e se constitui numa das raras experiências de planejamento integrado de um conjunto de cidades no contexto nacional.

\section{PROCEDIMENTOS METODOLÓGICOS}

Os estudos de Hall (2005) demonstraram a importância e a complexidade da experiência de planejamento da TVA, que, diferentemente do planejamento isolado de apenas uma cidade, preconizava o planejamento integrado do território compreendendo um conjunto de cidades e seus recursos ambientais.

O PDLF pode ser entendido como uma importante medida compensatória voltada ao enfrentamento dos danos causados aos municípios da região pelo processo de implantação do Lago de Furnas. Esse Plano configura-se ainda como uma das principais experiências de planejamento da TVA no Brasil, considerando a extensão do território do entorno do Lago de Furnas e o conjunto de municípios abordados.

O PDFL, apesar de sua relevância histórica, ainda é um documento pouco conhecido e de difícil acesso, pois as Prefeituras e as bibliotecas da região não possuem o documento em seus acervos. O estudo do PDLF poderia estabelecer uma importante contribuição para a compreensão da região do entorno do Lago de Furnas e, ao mesmo tempo, apontar alternativas e diretrizes para o planejamento integrado desse território.

Neste artigo, destacaram-se as principais diretrizes de desenvolvimento local e regional do PDLF, propostas em 1975, identificando as suas principais influências e possíveis desdobramentos no contexto atual do território do entorno do Lago de Furnas. 
Para a identificação dos impactos socioambientais causados pelo processo de implantação do Lago de Furnas, tomou-se como referência os trabalhos desenvolvidos por Contrin (1994) e Lemos Júnior (2010). Foram ainda considerados os relatos produzidos pelo jornalista José Franco, no período de 1959 a 1963, para a revista O Cruzeiro, registrados no acervo digital da Biblioteca Nacional.

A análise do conteúdo PDLF foi desenvolvida a partir de arquivos eletrônicos disponibilizados pela Fundação João Pinheiro de Belo Horizonte, que possui os originais do plano em seu acervo. As principais diretrizes regionais do PDLF foram identificadas e registradas no Quadro 1, incluso neste artigo. Foram visitados os seguintes municípios em Minas Gerais: Alfenas, Areado, Carmo do Rio Claro, Capitólio e Guapé, para identificação das áreas que foram objeto de propostas específicas do PDLF.

Foram realizadas quatro entrevistas com a secretaria executiva da Associação dos Municípios do Lago de Furnas (ALAGO) no município de Alfenas, com o objetivo de identificar as ações de planejamento e de integração regional que foram desenvolvidas desde a fundação da entidade.

Para Marconi e Lakatos (2012), a entrevista é entendida como uma técnica de pesquisa acadêmica para obtenção de informações sobre determinado assunto através de um diálogo profissional. Para esta pesquisa, foi adotada a técnica de entrevista não estruturada, que compreende a aplicação de perguntas abertas, nas quais o entrevistado tem oportunidade de apresentar uma abordagem livre e ampla sobe as questões (MARCONI; LAKATOS, 2012).

Na aplicação das entrevistas para a elaboração deste artigo, foram formuladas perguntas abertas voltadas aos seguintes temas: aplicação das propostas do PDLF; o sistema organizacional da ALAGO; experiências de planejamento e integração regional.

A seguir, foi analisado um conjunto de documentos levantados junto a ALAGO, entre os quais, merece destaque: os Boletins Informativos da ALAGO; o Diagnóstico Técnico das Condições de Saneamento dos Municípios da Região do Lago de Furnas de 2005; os relatórios da campanha dos Planos Diretores Municipais de 2006; e o Plano Diretor de Recursos Hídricos do Lago de Furnas de 2013. Esta pesquisa permitiu a identificação das experiências contemporâneas de planejamento e integração regional promovidas no território do entorno do Lago de Furnas.

Uma quinta reunião foi realizada com a diretoria ALAGO, para apresentação dos resultados dos levantamentos.

Os procedimentos metodológicos adotados objetivaram a explicação de uma experiência de planejamento do passado, ou seja, o PDLF de 1975, para verificação de suas influências no contexto contemporâneo.

\section{O PLANO DE DESENVOLVIMENTO DO LAGO DE FURNAS DE 1975}

A Usina de Furnas foi implantada no sudoeste de Minas Gerais, nas décadas de 1950 e 1960, entre 1956 a 1965, atendendo ao projeto desenvolvimentista do Plano de Metas do Governo Juscelino Kubitschek. Esta obra de infraestrutura foi executada com o objetivo de atender parte do conteúdo da Meta de Energia garantindo o fornecimento de eletricidade para os estados de São Paulo, Rio de Janeiro e Minas Gerais (BRASIL, 1957; CONTRIN, 1994).

A barragem construída no encontro do Rio Grande com o Rio Sapucaí, na região conhecida como 'Corredeiras de Furnas', possibilitou a execução da primeira Usina Hidrelétrica Brasileira, de grande porte, viabilizando o desenvolvimento da Região Sudeste do Brasil, porém, simultaneamente, provocou graves impactos socioeconômicos nos municípios atingidos pelo grande lago. 
O Lago de Furnas com os seus dois braços do Rio Grande e do Rio Sapucaí, inundou aproximadamente $1400 \mathrm{~km}^{2}$ terras, atingindo 32 municípios, provocando cerca de 8.000 desapropriações, atingindo desde pequenas casas até grandes fazendas. Muitas pessoas perderam seus bens e suas condições de subsistência na região (LEMOS JÚNIOR, 2010).

Em 1963, no governo do Presidente João Goulart, com o fechamento da barragem, a paisagem da região começou a se transformar, com a inundação de vilarejos, fazendas e cidades. São José da Barra, na época, distrito do município de Alpinópolis, com 3.000 habitantes, foi totalmente inundado, obrigando FURNAS a construir uma nova cidade (LEMOS JÚNIOR, 2010).

Além de São José da Barra, a cidade de Guapé, que na época possuía 15.000 habitantes, foi inundada pelo lago obrigando também FURNAS a construir uma nova cidade, numa região mais alta do município. Outras localidades mineiras como Santo Hilário, Itaci, Barranco Alto, Pontalete, Araúna, Porto Mendes, Capitólio, Fama e Boa Esperança também tiveram parte do seu território atingido pelo Lago de Furnas (FRANCO, 1959).

Entretanto o Lago de Furnas passou a interligar um conjunto de municípios, dos quais muitos deles, até então, não desenvolviam significativas relações socioeconômicas e culturais conformando então, uma nova região formada pelos 32 municípios do seu entorno.

Em 12 de maio de 1965, já no período do Regime Militar, o General Humberto Castello Branco inaugurou oficialmente a Usina Hidrelétrica de Furnas. Com a conclusão das obras, a geografia da região foi profundamente transformada passando a ser caracterizada pela lâmina d'água do Lago de Furnas, interligando um conjunto de municípios que sofreram consideráveis impactos socioeconômicos e ambientais.

Na década de 1970, o Governo de Minas Gerais passou a estudar as possibilidades de implantação de projetos de desenvolvimento na região afetada pela inundação do Lago de Furnas. Na época, uma comissão técnica formada por membros da Secretaria da Indústria, Comércio e Turismo de Minas Gerais e de FURNAS visitaram a TVA nos Estados Unidos para conhecer as experiências de utilização turística, industrial e comercial dos lagos criados no Vale do Tennessee para a produção de energia elétrica e para a regularização da vazão dos rios (MINAS GERAIS, 1975).

Mais tarde, como já mencionado, A. J. Gray, membro do corpo técnico da TVA, foi contratado pelo Governo de Minas Gerais, (através da Secretaria de Indústria, Comércio e Turismo) e por FURNAS, como consultor para a coordenação do PDLF, contando com o apoio de uma equipe técnica composta por profissionais indicados pelas entidades contratantes. O PDLF foi concluído em fevereiro de 1975.

O plano estruturou-se a partir de três objetivos iniciais: estabelecer uma linha de ação para o desenvolvimento da região envoltória ao Lago de Furnas; escolha da área prioritária para desenvolvimento; e indicações para implantação de um sistema gestor para a execução do plano.

A Barragem de Furnas, com 127 metros de altura e 550 metros de comprimento na sua crista, foi construída no desfiladeiro do Rio Grande, situada a jusante da confluência deste com o Rio Sapucaí. O lago se estendeu por 240 km do braço do Rio Grande e 170 km do braço do Rio Sapucaí, tendo uma superfície de $1.260 \mathrm{~km}^{2}$ e um perímetro de aproximadamente $3.000 \mathrm{~km}$.

O PDLF considerou o Lago de Furnas como importante equipamento turístico a ser usufruído pela população da região sudeste do Brasil, que na época abrigava aproximadamente $40 \%$ da população nacional. Os autores do plano indicavam a implantação de atividades recreativas e turísticas junto às margens do Lago de Furnas. 
O diagnóstico do plano identificava na época o predomínio de pequenas propriedades agrícolas no entorno do Lago, e previa que, com os avanços tecnológicos, haveria uma fusão das terras com o surgimento de propriedades maiores que provocariam a diminuição da oferta do emprego rural. Para evitar a migração dos moradores da região rumo às grandes cidades brasileiras, o PDLF apontava a necessidade da criação de novos postos de trabalho na região. O plano teria uma duração de 20 anos, com revisões a cada cinco anos, pretendendo nas suas propostas de desenvolvimento aumentar a renda da população rural, controlar a erosão e industrializar as pequenas cidades da região.

O programa de desenvolvimento compreendia o aprimoramento da infraestrutura dos núcleos urbanos com a implantação de distritos industriais planejados, programas habitacionais de qualidade e capacitação da mão de obra local para o trabalho nas futuras indústrias que deveriam ser implantadas na região.

O plano previa ações voltadas à melhoria das técnicas agrícolas utilizadas; aumento da produção e renda rural; reflorestamento e controle da erosão das terras do entorno do Lago de Furnas. Ao aprimorar as técnicas agrícolas na região, o plano pretendia evitar os efeitos da erosão do solo bem como a condução de fertilizantes para dentro do Lago de Furnas. O descontrole do processo poderia provocar o crescimento excessivo da vegetação aquática, prejudicando os pretendidos usos recreativos e de pesca no lago. Programas de reflorestamento seriam implantados em toda a extensão do lago objetivando reduzir-Ihe o assoreamento e a turvação.

A piscicultura comercial foi indicada como uma atividade econômica possível de ser implantada no Lago de Furnas.

A inexistência de um sistema regional de rodovias pavimentadas interligadas aos grandes centros populacionais da Região Sudeste se apresentava, na época, como o principal entrave para o desenvolvimento turístico da região. O Plano indicava ainda a necessidade de implantação de um aeroporto na região.

O Plano apontava para as características das águas do sul do Lago de Furnas, que, nos períodos de chuvas, tornavam-se turvas e sem atrativos para o turismo. Já a metade norte do lago, onde a água seria cristalina o ano todo, foi indicada como a região mais adequada às atividades recreativas e turísticas, como mostra a Figura 1. 
Figura 1 - Mapa de turvação do Lago de Furnas

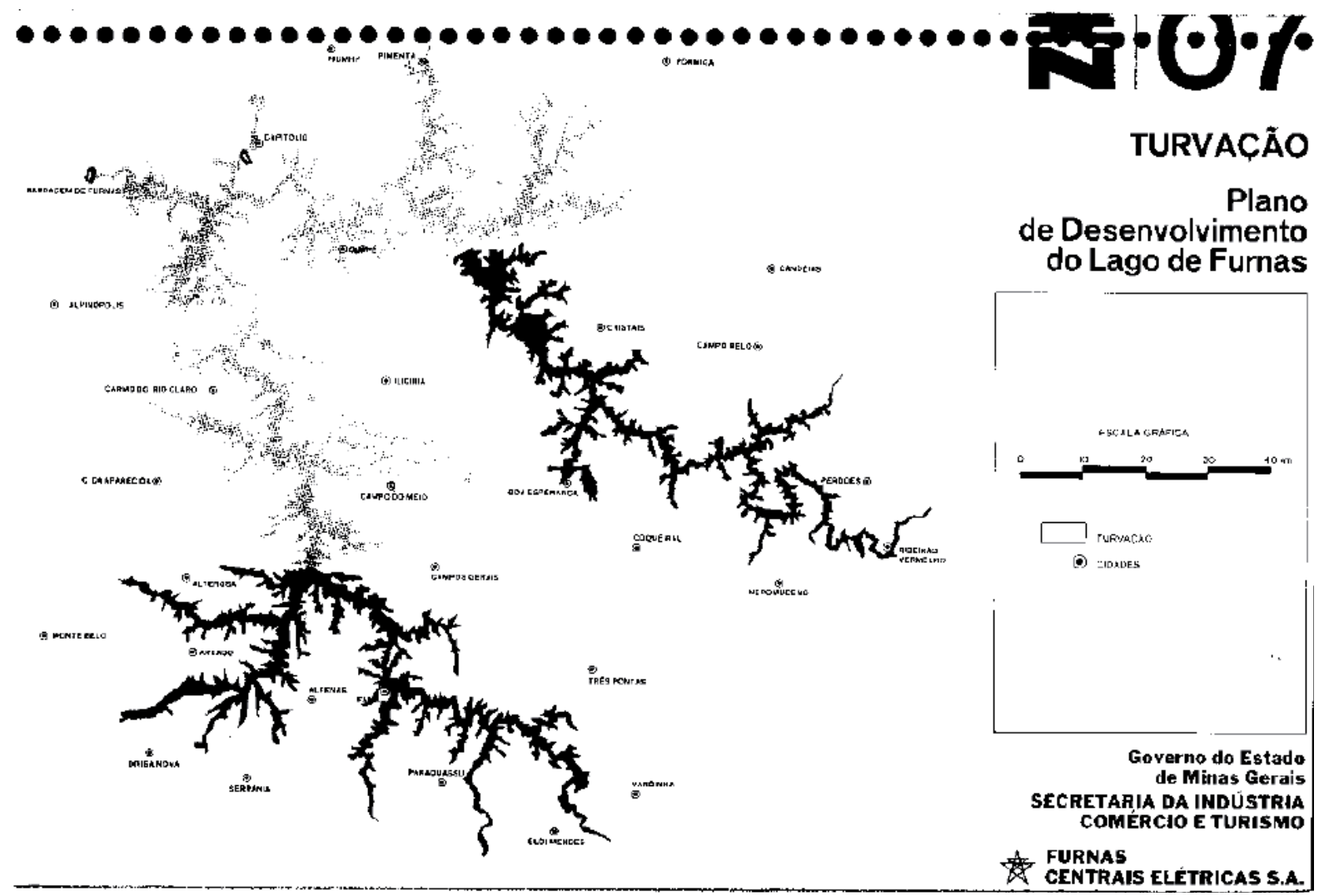

Fonte: Minas Gerais, 1975.

O PDLF identificou diferentes atributos para terras situadas ao norte e ao sul do Lago de Furnas. Na região norte, existiam terrenos inclinados, montanhas, altos platôs, escarpas íngremes e cânions, que poderiam ser explorados com atividades turísticas. Já a região sul era caracterizada por colinas suavemente onduladas, com pouca variedade morfológica, possuindo solos indicados para utilização agrícola.

Destacavam-se as características geológicas da região norte, a montante da barragem, onde o lago se aprofundava em vários cânions, que podiam ser observados através de incursões com barcos. Esses cânions tinham relevantes características cênicas, que podiam ainda ser observados através de mirantes que existiam no topo das escarpas. O PDLF, destacando os atributos paisagísticos dessa região, indicava a adoção de ações específicas para a exploração das qualidades desse território.

De certa maneira, o PDLF apresentou uma proposta de zoneamento para o território no entorno do Lago de Furnas, indicando usos agrícolas para a região sul e a implantação de florestas, pastagens e um conjunto de atividades turísticas para a região norte.

O plano reconhecia que as atividades turísticas não poderiam se sobrepor ao objetivo básico da execução do Lago de Furnas, ou seja, a produção de energia elétrica.

A pesca turística foi indicada como a principal atração do lago. Sugeria-se o desenvolvimento de um conjunto de eventos que deveriam ser programados para divulgação dos recursos turísticos do Lago de Furnas, como competições estaduais e nacionais de esportes náuticos e concursos de pesca. 
Para a implantação das atividades turísticas na região norte do Lago de Furnas, o território foi divido em quatro áreas, com o objetivo de reduzir os custos de manutenção e ampliar a atratividade dos empreendimentos turísticos.

A Área 01, compreendida à margem direita do Lago de Furnas, desde a barragem até a cidade de Capitólio, era considerada como área prioritária para desenvolvimento. Os cânions, quedas d'água e as águas cristalinas do Lago de Furnas existentes naquela região foram considerados como elementos turísticos estratégicos. Propunha-se a implantação de parques, equipamentos recreativos, um complexo turístico privado de alto padrão e casas de veraneio e para finais de semana.

Para a Área 02, localizada em Santo Hilário, distrito do município de Pimenta, recomendava-se a implantação de equipamentos turísticos, comerciais e casas de veraneio. Sugeria-se o reflorestamento da montanha, a implantação de trilhas para passeio a pé e a cavalo, e mirantes nos pontos mais altos voltados para as amplas vistas do Lago de Furnas. Os investimentos em Santo Hilário deveriam iniciar-se cinco anos após a implantação das melhorias na Área 01.

A Área 03 situava-se em Carmo do Rio Claro, no braço do lago correspondente ao Rio Sapucaí, recomendava-se também a implantação de um complexo turístico privado em vinte anos após a implantação das obras previstas para a Área 01. Recomendava-se que a pequena capela situada no alto da Serra Tormenta, a mais de 1200 metros de altura, se transformasse num mirante turístico.

Para a Área 04, situada à margem esquerda do lago da ponte de Santo Hilário até a barragem de Furnas, estava prevista a melhoria dos acessos rodoviários e por balsas, e a implantação de equipamentos recreativos. Os investimentos para Área 04 deveriam ser implantados depois de vinte anos do início das obras na Área 01.

Propunha-se a melhoria do sistema viário com investimentos em rodovias, ferrovias e linhas aéreas. Entretanto existiam poucas referências ao transporte aquático por barcos e balsas, que haviam se transformado em um dos principais meios de transporte para interligação dos municípios atingidos pelo Lago de Furnas.

O plano previa a implantação de um sistema de parques composto por nove projetos situados no entorno do Lago de Furnas, que, além de promover o lazer e o turismo, atuariam como importantes instrumentos de preservação dos recursos ambientais regionais.

O equilíbrio entre os projetos de desenvolvimento e a preservação dos recursos ambientais do território deveria ser promovido por um Centro de Treinamento e Pesquisa de Recursos e Meio Ambiente que deveria ser implantado no entorno do Lago de Furnas.

Para acompanhamento do processo de implantação do PDLF, foi proposta a criação da Agência de Desenvolvimento de Desenvolvimento do Lago de Furnas que deveria ainda controlar o desenvolvimento regional, implantar e operar os sistemas de recreação.

A implantação desses projetos deveria provocar um alto fluxo de pessoas para a região, exigindo assim ações específicas para as questões sanitárias. O PDLF sugeria que o abastecimento de água poderia ser provido pelo próprio Lago de Furnas depois de tratamentos específicos em conjunto com outras fontes alternativas. Criticava-se a adoção de tanques sépticos para os esgotos domésticos, uma vez que os possíveis resíduos seriam direcionados diretamente ao Lago de Furnas. Recomendava-se a implantação de sistemas anaeróbicos para o tratamento do esgoto que seria produzido na região.

As Diretrizes do Plano de Desenvolvimento do Lago de Furnas são apresentadas no Quadro 1: 
Quadro 1 - Diretrizes do Plano de Desenvolvimento do Lago de Furnas

\begin{tabular}{|c|c|}
\hline \multicolumn{2}{|r|}{ DIRETRIZES DO PDLF } \\
\hline \multicolumn{2}{|c|}{ CONCENTRAÇÃO DE INSTALAÇÕES RECREACIONAIS NA METADE NORTE DO LAGO DE FURNAS } \\
\hline \multicolumn{2}{|c|}{ 1.1 ÁREA 01- Margem direita do Lago de Furnas desde a barragem até Capitólio } \\
\hline \multicolumn{2}{|c|}{ 1.2 ÁREA 02-Santo Hilário } \\
\hline \multicolumn{2}{|l|}{ 1.3 ÁREA 03-Carmo do Rio Claro } \\
\hline \multicolumn{2}{|c|}{ 1.4 ÁREA 04- Margem esquerda do Lago de Furnas de Santo Hilário até a barragem. } \\
\hline \multicolumn{2}{|c|}{ MELHORIAS NA REDE VIÁRIA } \\
\hline \multicolumn{2}{|c|}{ IMPLANTAÇÃO ÁREAS DE ACESSO PÚBLICO E UM SISTEMA DE PARQUES LOCAIS } \\
\hline 3.1 Parque de Barranco Alto & 3.6 Parque de Guapé \\
\hline 3.2 Parque de Campo do Meio & 3.7 Parque de Alterosa e Areado \\
\hline $\begin{array}{l}\text { 3.3 Parque de Capitólio (que deveria servir } \\
\text { também Piumhi) }\end{array}$ & 3.8 Parque de Alfenas (que deveria servir as cidades do Sul) \\
\hline 3.4 Parque de Carmo do Rio Claro & \multirow{2}{*}{$\begin{array}{l}\text { 3.9 Parque de Boa Esperança (que deveria servir Três Pontas, } \\
\text { Varginha, Três Corações, Coqueiral, Nepomuceno e outras } \\
\text { localidades do Sudoeste Mineiro) }\end{array}$} \\
\hline 3.5 Parque de Fama & \\
\hline \multicolumn{2}{|c|}{ IMPLANTAÇÃO DE UM CENTRO DE TREINAMENTO E PESQUISA DE RECURSOS E MEIO AMBIENTE } \\
\hline \multicolumn{2}{|c|}{ CRIAÇÃO DE UMA AGÊNCIA DE DESENVOLVIMENTO DO LAGO DE FURNAS } \\
\hline
\end{tabular}

Fonte: Minas Gerais, 1975.

\section{OS REFLEXOS CONTEMPORÂNEOS DO PLANO DE DESENVOLVIMENTO DO LAGO DE FURNAS}

A maioria das propostas e diretrizes do Plano de Desenvolvimento do Lago de Furnas não foram implantadas, entretanto a diretriz da criação da Agência de Desenvolvimento do Lago de Furnas parece ter sido plenamente atendida com a criação da Associação dos Municípios do Lago de Furnas (ALAGO), que foi instituída em 1994 com o objetivo estatutário de promover e induzir o desenvolvimento integrado dos municípios, nas áreas de saneamento básico, meio ambiente, transportes e turismo em toda a região do Lago de Furnas. Caberia ainda à ALAGO: o desenvolvimento da indústria; do comércio; da agricultura regional; permanente saneamento do lago; preservação dos mananciais e o saneamento básico dos municípios do Lago de Furnas (ASSOCIAÇÃO DOS MUNICÍPIOS DO LAGO DE FURNAS [ALAGO], 2008).

Uma das experiências mais importantes de planejamento integrado do território desenvolvido pela ALAGO, em conjunto com o Ministério das Cidades, o Governo do Estado de Minais Gerias, Furnas Centrais Elétricas e outras entidades locais e regionais, foi a coordenação do processo de elaboração de 50 Planos Diretores Participativos para os municípios situados no entorno do Lago de Furnas, no período de 2006 a 2007 (Figura 2). 
Figura 2 - Mapa do Lago de Furnas e dos Municípios do seu Entorno

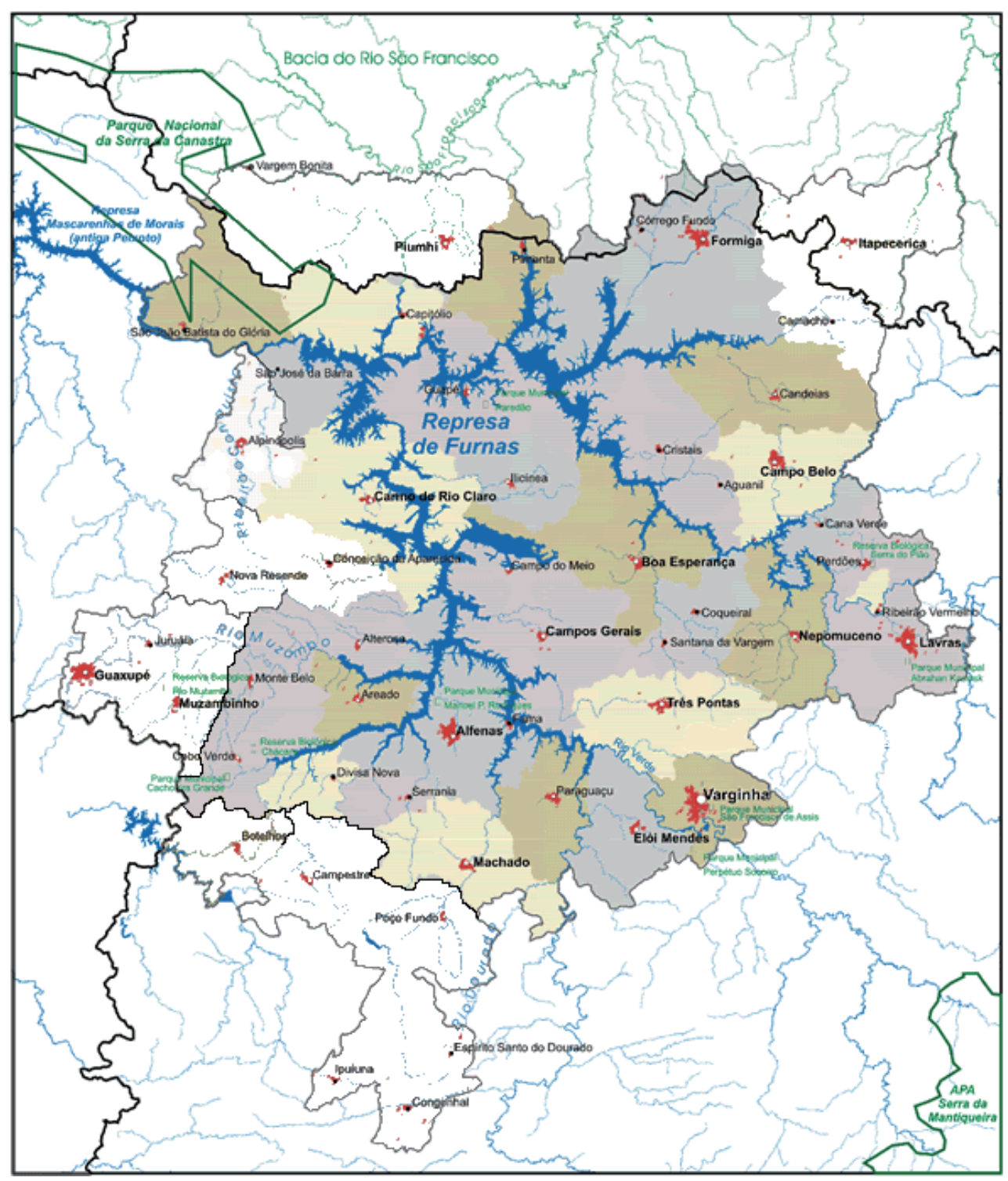

Fonte: ALAGO, 2008.

Já as implantações dos previstos empreendimentos turísticos e recreativos não obedeceram a diretrizes centralizadas de planejamento. Ao contrário, foram o resultado de projetos e interesses específicos da iniciativa privada que se concentraram, como previa o PDLF, na metade norte do Lago de Furnas, onde as águas eram cristalinas e as montanhas e escarpas ofereciam oportunidades estratégicas para os negócios turísticos.

Em 1979, foi implantado, no município de Capitólio, o bairro Engenheiro José Mendes Júnior, conhecido como Balneário Escarpas do Lago, compreendendo um complexo de residências de veraneio com espaços de lazer e recreação. O empreendimento foi construído numa região próxima ao principal atrativo turístico da região, ou seja, os cânions do Lago de Furnas, que são visitados através de passeios de barcos (Figura 3). Atualmente existem no balneário, aproximadamente 1000 casas de alto padrão que são, na maioria das vezes, utilizadas nos finais de semana e temporada (CAPITÓLIO, 2016). 
Figura 3 - Cânions do Lago de Furnas

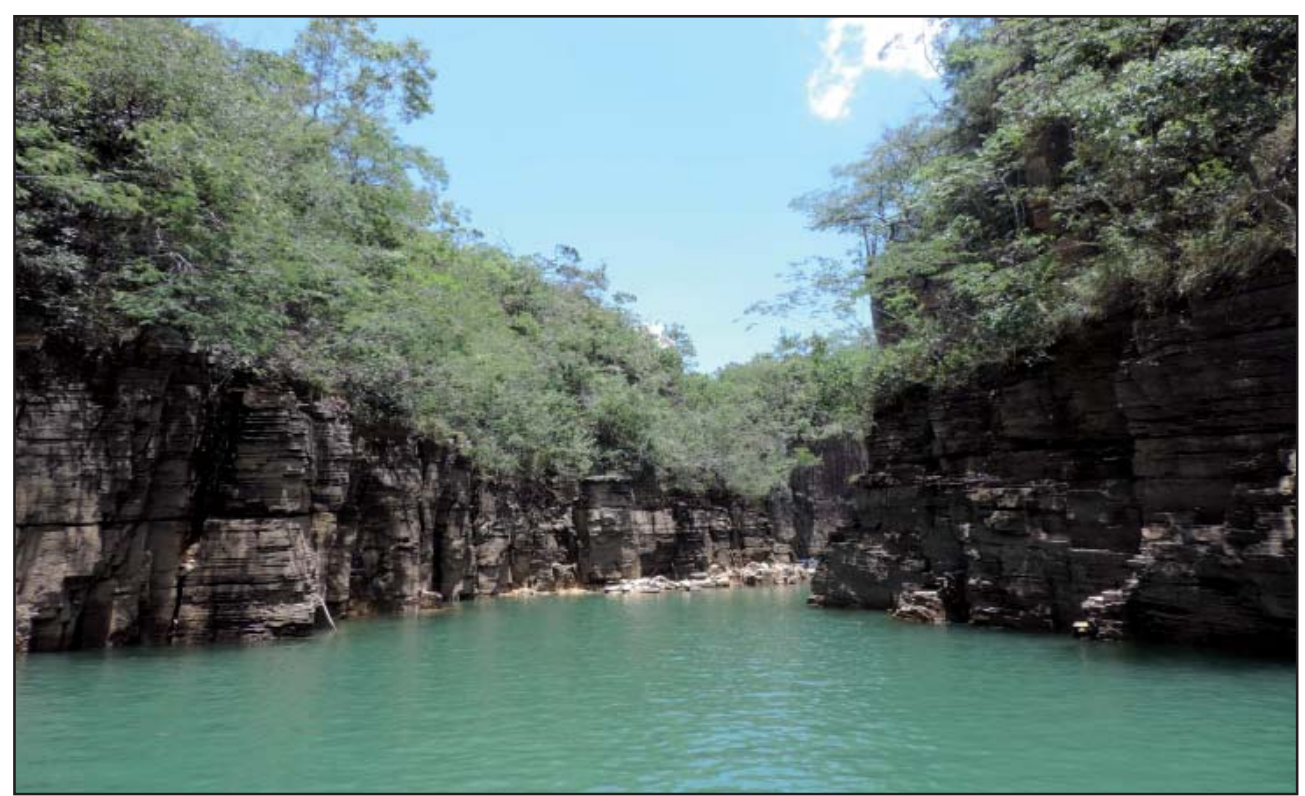

Fonte: Arquivo pessoal dos autores.

Outros projetos imobiliários semelhantes foram implantados na região norte do Lago de Furnas com o mesmo objetivo de explorar a qualidade das águas e as paisagens dessa região. Os empreendimentos turísticos, contudo, enfrentaram o problema da depleção, ou seja, a variação do nível do lago, necessária para o processo de produção de energia elétrica na Usina de Furnas. Os municípios situados no entorno do Lago de Furnas que exploram atividades turísticas, passaram a sofrer consideráveis impactos socioeconômicos quando ocorria a redução do nível do reservatório. Esse fato agravou-se com grande estiagem de 2015, que provocou o fechamento de vários estabelecimentos voltados à exploração turística na região.

Nos períodos em que o nível do lago ficava mais baixo, grandes extensões de terra se formavam transformando a paisagem e comprometendo a exploração das atividades turísticas. Pequenas lagoas se formavam transformando-se em focos de mosquitos e pernilongos que afetavam a população local e as atividades turísticas. Para o enfrentamento desse problema o município de Boa Esperança construiu uma barragem para manutenção do nível do lago nos períodos de estiagem (BOA ESPERANÇA, 2013).

Apesar de a proposta do PDLF de implantação de um sistema de parques, composto por nove parques, não ter sido viabilizada, existem hoje nos municípios do entorno do Lago de Furnas oito importantes Unidades de Conservação: parte do Parque Nacional da Serra da Canastra; o Parque Estadual da Serra da Boa Esperança; o Refúgio da Vida Silvestre Mata Lagoa do Fundão e o Monumento Natural da Ilha das Pedras em Formiga; a APA do Rio Machado, que abrange o território de onze municípios; a APA de Coqueiral no município de Coqueiral; a APA de Cabo Verde e do Pau d'alho no município de Cabo Verde. Existem ainda na região onze Reservas Particulares do Patrimônio Natural distribuídas nos municípios de Alfenas, Alterosa, Carmo do Rio Claro, Itapecerica, Machado, Monte Belo e Três Pontas (ALAGO, 2013).

Esse conjunto de Unidades de Conservação, ainda que não sejam reconhecidas como um sistema integrado, acaba por desempenhar um importante papel na preservação dos recursos ambientais da região e ainda, serem mais bem explorados com projetos turísticos sustentáveis. 
Os investimentos previstos para as rodovias, ferrovias e linhas aéreas não se viabilizaram. Entretanto o transporte aquático pelo Lago de Furnas através de barcos e balsas se apresentou como uma nova opção a ser explorada. Um dos projetos do Plano Diretor de Recursos da Bacia Hidrográfica do Entorno do Lago de Furnas elaborado em 2013 é a implantação de uma hidrovia ligando os municípios de Alfenas e Formiga (ALAGO, 2013).

A referida hidrovia, com aproximadamente $250 \mathrm{~km}$ de extensão, interligaria a região norte e a região sul do Lago de Furnas, procurando apoiar o turismo e o transporte de cargas. Pensava-se ainda em futuramente estabelecer uma interligação da hidrovia do Lago de Furnas com a hidrovia Tietê-Paraná.

As recomendações para o desenvolvimento da piscicultura com objetivos turísticos e comerciais se concretizaram, configurando-se hoje como uma importante fonte de geração de renda para as famílias do entorno do Lago de Furnas (Figura 4). Atualmente existem mais de 500 piscicultores e mais de 5.000 tanques de criação de peixes distribuídos nos municípios do entorno do Lago de Furnas (ALAGO, 2014).

Figura 4 - Tanques de piscicultura no Lago de Furnas no município de Alfenas

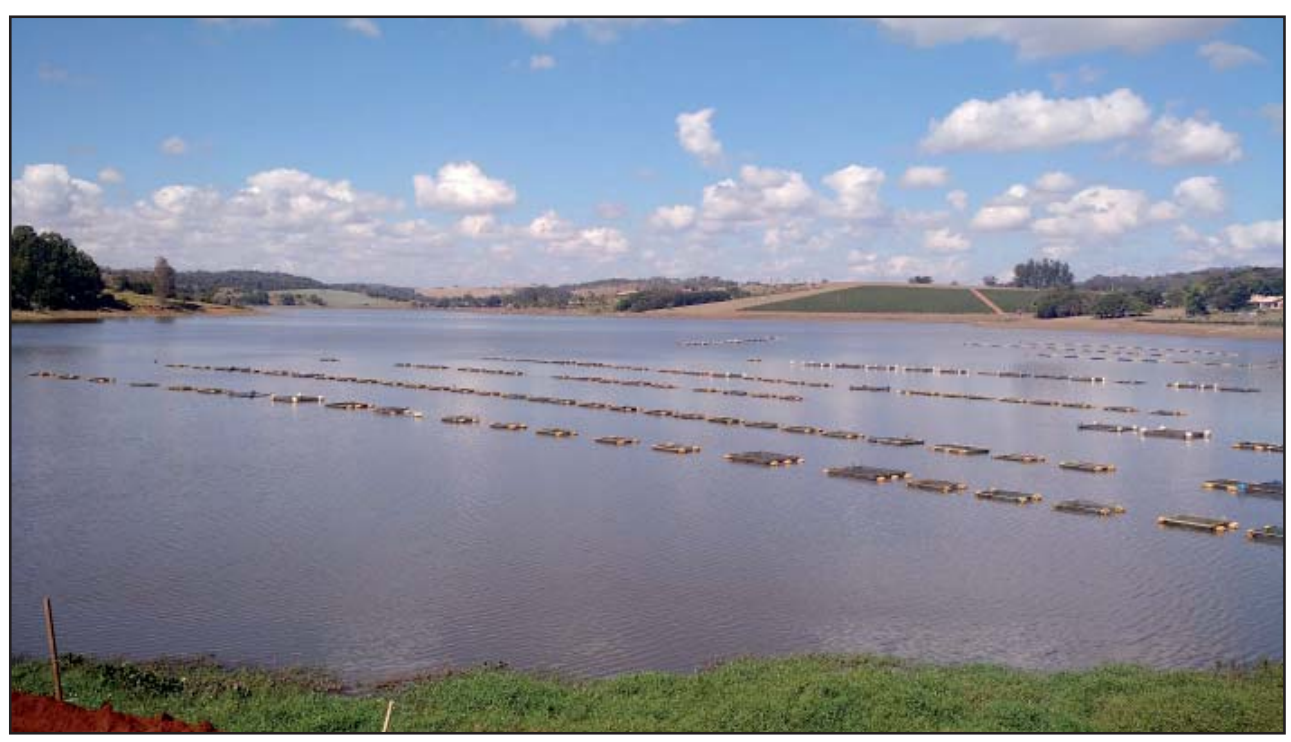

Fonte: Arquivo pessoal dos autores.

Já as preocupações apresentadas no PDLF relacionadas às questões sanitárias transformaram-se num dos principais desafios a serem enfrentados pelos municípios do entorno do Lago de Furnas.

\section{O CONTEXTO CONTEMPORÂNEO DO ENTORNO DO LAGO DE FURNAS}

Em 2002, foi criada a Unidade de Planejamento e Gestão de Recursos Hídricos Grande 3, do Entorno do Lago de Furnas (UPGRH GD3 FURNAS) conformando um território de 16.507 $\mathrm{km}^{2}$. A UPGRH GD3 FURNAS abriga uma população de aproximadamente 863.547 distribuída em 48 municípios. A grande maioria desses municípios é de pequeno porte, ou seja, com uma população menor que 20.000 habitantes. Os dois municípios mais populosos são: Alfenas com 73.774 habitantes e Formiga com 65.128 habitantes. Existem ainda 19 municípios com menos de 10.000 habitantes. 
A economia da região é predominantemente voltada para agricultura e pecuária. No setor agrícola destacam-se as culturas de café, milho, feijão, cana de açúcar e arroz. As pastagens ocupam aproximadamente $36 \%$ do território da UPGRH GD3 FURNAS. Por outro lado, as áreas urbanas ocupam apenas $0,7 \%$ do território. A região vive, contudo, um processo de esvaziamento do espaço rural provocado principalmente pela falta de oportunidades de emprego e renda no campo (ALAGO, 2013a).

Outra importante fonte de renda dos municípios atingidos pelo Lago de Furnas são os royalties pagos por Furnas Centrais Elétricas (FURNAS) devido aos danos ambientais e socioeconômicos causados na região pela produção de energia elétrica. Essa contribuição definida como Compensação Financeira pela utilização dos Recursos Hídricos (CMPFRH) tem sido objeto disputas e demandas, uma vez que os municípios da região entendem que os valores pagos por FURNAS deveriam ser aumentados. A diminuição da produção de energia elétrica causada pelas estiagens dos últimos anos tem provocado à diminuição da CMPFRH, causando sérios problemas financeiros para os municípios da região (LEMOS JÚNIOR, 2010; VIANNEY, 2008; ALVES, 2013; AGÊNCIA NACIONAL DE ENERGIA ELÉTRICA -ANEEL, 2016).

Já as atividades turísticas no entorno do Lago de Furnas ainda carecem de uma melhor estruturação. A deficiência da rede viária, a poluição do lago por redes de esgoto e a ocupação imobiliária irregular nas margens são apontadas como fatores extremamente prejudiciais à exploração turística dessa região (ALAGO, 2013a; LEMOS JÚNIOR, 2010).

Em 2005, a ALAGO coordenou a elaboração do Diagnóstico Técnico das Condições de Saneamento dos Municípios da Região do Lago de Furnas desenvolveu uma análise das condições dos sistemas de abastecimento de água, esgotamento sanitário, drenagem de águas pluviais e manejo de resíduos sólidos dos municípios da região. Na época, a população total dos 52 municípios estudados era de 1.120 .323 habitantes, sendo que aproximadamente $85 \%$ viviam na zona urbana e aproximadamente $15 \%$ viviam em distritos municipais e na zona rural (ALAGO, 2005). $\mathrm{Na}$ época quase todo o esgoto produzido pelos municípios da região desaguava in natura no Lago de Furnas pelos rios da bacia. Todas as cidades possuíam rede coletora de esgoto, contudo, em apenas 9 cidades e 8 distritos o esgoto era parcialmente tratado (ALAGO, 2005).

Mais tarde o Plano Diretor de Recursos Hídricos da Bacia Hidrográfica do Entorno do Lago de Furnas identificou a melhoria da qualidade das águas como um dos principais objetivos a serem enfrentados. Esse objetivo seria conquistado através de um grande acordo que deveria ser construído com os municípios do entorno do Lago de Furnas compreendendo: a redução dos impactos causados pelos usos urbanos, a recuperação das áreas verdes nas margens dos rios e a proteção das nascentes e aquíferos (ALAGO, 2013b).

Se num primeiro momento foi o Lago de Furnas que causou relevantes danos e prejuízos aos municípios e a população afetada, agora são estes mesmos municípios que hoje provocam consideráveis impactos ambientais ao lago com a emissão de seus esgotos domésticos.

Mesmo assim a região norte do Lago de Furnas, indicada para usos turísticos pelo PDFL, tem recebido nos últimos anos grandes empreendimentos imobiliários relacionados à implantação de marinas, aeroclubes, condomínios de alto padrão e complexos hoteleiros. A maioria dos projetos tem se concentrado no território dos municípios de Capitólio e Guapé, explorando as paisagens, os cânions e as águas cristalinas daquela região (ÚLTIMAS NOTíCIAS, 2011).

Entretanto muitos desses mesmos empreendimentos estão enfrentando demandas judiciais por não respeitarem a exigência legal dos cem metros da área de preservação permanente 
no entorno do Lago de Furnas. O Ministério Público Federal tem procurado impedir, através de ações judiciais, a implantação desses empreendimentos turísticos considerando os relevantes impactos ambientais causados com a supressão da vegetação nativa (BRASIL, 2015).

Os projetos turísticos implantados no entorno do Lago de Furnas não obedeceram a um projeto estruturado que integrasse todo o território como pretendia o PDLF. Ao contrário, os principais empreendimentos foram resultado de iniciativas específicas voltadas a um público de alta renda que visita a região em determinadas épocas do ano.

Já a estratégia da TVA no Vale do Tennessee, demonstrada no PDFL, promoveu o desenvolvimento regional através da gestão integrada dos recursos hídricos e ambientais daquele território. As experiências de planejamento regional da TVA procuraram explorar os usos múltiplos das águas dos reservatórios compreendendo: o controle das enchentes, a geração de energia, a navegação, a recreação e o saneamento ambiental (LOCARNO, 2008 ; VIANNA, 2015).

O PDLF previu que a agência de desenvolvimento do Lago de Furnas deveria desenvolver projetos cooperativos e integrados voltados aos seguintes temas: aprimoramento dos métodos de cultivo e comercialização dos produtos agrícolas; desenvolvimento e exploração dos recursos florestais; controle da erosão; industrialização e exploração turística do Lago.

Essas tarefas têm sido, em grande parte, assumidas pela ALAGO, que passou a se configurar como o principal elo aglutinador da região. A ALAGO possui trinta e sete municípios associados, que se reúnem periodicamente para deliberarem sobre temas e projetos de desenvolvimento regional. Além da já citada campanha dos Planos Diretores de 2006, que consolidou a integração dos municípios da região e do processo de elaboração do PDRH FURNAS, e identificou os principais desafios ambientais deste território, a ALAGO desenvolve hoje um conjunto de projetos e programas voltados à preservação ambiental e a melhoria dos serviços turísticos da região.

\section{CONCLUSÃO}

O presente artigo procurou contextualizar a experiência da elaboração da PDLF, entendendo esse documento como uma primeira estratégia de enfrentamento dos impactos causados pelo Lago de Furnas. Identificou-se ainda esse processo, como iniciativa fundamental para a consolidação de um projeto de desenvolvimento integrado do território do entorno do Lago de Furnas.

O referencial teórico permitiu a compreensão da importância das teorias urbanísticas que superam os limites das cidades e que passaram a abordar o planejamento integrado do território regional. Nesse contexto, as experiências de planejamento da TVA que aliaram a exploração dos recursos ambientais com projetos de desenvolvimento socioeconômico da região do Vale do Tennessee, ainda se apresentam como um modelo possível para o planejamento local e regional. De maneira semelhante às abordagens de Howard, para as 'Cidades Jardins', que contemplaram um conjunto de cidades cooperativas integradas num sistema de cidades voltadas ao enfrentamento de problemas e demandas coletivas.

No contexto contemporâneo, o foco no enfrentamento dos problemas urbanísticos e estruturais das grandes metrópoles tem abrandado o desenvolvimento de uma reflexão abrangente sobre a questão regional e dos pequenos e médios municípios envolvidos por contextos rurais ou naturais.

O PDLF aponta em outra direção, ou seja, o planejamento do território de um conjunto de municípios não conurbados que sofreram um significativo impacto socioeconômico e ambiental com a implantação do Lago de Furnas. 
Ao mesmo tempo em que o PDFL tomou como base uma premissa questionável, ou seja, a exploração do lago como recurso turístico regional, ele apontou para a necessidade de uma abordagem abrangente do território com o estabelecimento de cinco diretrizes que objetivariam a promoção do desenvolvimento socioeconômico e a preservação ambiental.

A proposta da implantação da Agência de Desenvolvimento do Lago de Furnas, que se materializou com criação da ALAGO em 1994, viabilizou a constituição de uma entidade regional voltada ao planejamento integrado do território. Nesse contexto, ao invés de cada município enfrentar seus problemas e demandas de maneira individualizada um organismo regional passou a viabilizar um processo participativo e cooperativo para o enfrentamento dos desafios regionais.

O resgate da experiência de planejamento integrado do território do entorno do Lago de Furnas, além de se configurar como uma contribuição para a compreensão dessa região e de uma revisão histórica dessa importante experiência de planejamento regional se apresenta hoje, como uma referência para o planejamento das pequenas e médias cidades brasileiras. Esses municípios carecem de recursos financeiros e de estruturas técnicas e organizacionais que viabilizem uma reflexão abrangente sobre um projeto de desenvolvimento regional. Por outro lado, esses mesmos municípios possuem, como foi indicado por Howard, um rico patrimônio ambiental que as metrópoles contemporâneas não possuem.

Nesse cenário, um possível modelo de desenvolvimento regional para essas pequenas e médias cidades do entorno do Lago de Furnas, não deve ser entendido como um conjunto de ideias pré-concebidas formuladas por equipes técnicas contratadas. Ao contrário, deve ser construído em conjunto com os municípios envolvidos, com processos participativos e revisões periódicas como o próprio PDLF previa. Assim esse conjunto de municípios que num primeiro momento sofreram os relevantes impactos socioambientais do processo de implantação do Lago de Furnas e que mais tarde descobriram que faziam parte de uma extensa região interligada pelo mesmo lago, possui hoje uma experiência acumulada que pode possibilitar a construção de um modelo de desenvolvimento referencial para as pequenas e médias cidades brasileiras, ou seja, um desenvolvimento baseado principalmente no enfrentamento do desafio da integração regional.

\section{REFERÊNCIAS}

AGÊNCIA NACIONAL DE ENERGIA ELÉTRICA (ANEEL) (Brasil). Relatórios da Compensação Financeira pela Utilização de Recursos Hídricos (CMPFRH). Mar. 2016. Disponível em: <http://www.aneel.gov.br/listacompleta/-/asset_publisher/9HySU9UbBbG2/content/id/14782141>. Acesso em: 17 nov. 2017.

ALLEN, H. C. História dos Estados Unidos da América. Rio de Janeiro: Forense, 1968.

ALVES, Vagner D. Municípios impactados por hidrelétricas querem mais recursos. A Folha Regional, Muzambinho, MG, 5 jul. 2013. Disponível em: <http://www.afolharegional.com/?url=artigos/regiao/ municipios-impactados-por-hidreletricas-querem-mais-recursos>. Acesso em: 17 nov. 2017.

ASSOCIAÇÃO DOS MUNICÍPIOS DO LAGO DE FURNAS (ALAGO). Diagnóstico tecnológico da piscicultura do Lago de Furnas (MG). Alfenas: ALAGO, 2014. Disponível em: <http://www.alago.org.br/imagens/image/ Noticias /DTP_Funas.pdf>. Acesso em: 26 jul. 2017.

PDRH FURNAS - plano diretor de recursos hídricos da Bacia Hidrográfica do entorno do Lago de Furnas - relatório parcial 1: diagnóstico da bacia hidrográfica. Alfenas: ALAGO, 2013a. Disponível em: <http://www.alago.org.br/imagens/image/PDRH\%20GD3\%20-\%20Diagn\%C3\%B3stico.pdf>. Acesso em: 13 nov. 2015.

PDRH FURNAS - Plano diretor de recursos hídricos da Bacia Hidrográfica do entorno do lago de Furnas. Relatório parcial 1: resumo executivo. Alfenas: ALAGO, 2013b. Disponível em: 
<http://www.alago.org.br/imagens/image/pdrh\%20gd3\%20-\%20resumo\%20executivo.pdf>. Acesso em: 6 jan. 2016.

ASSOCIAÇÃO DOS MUNICÍPIOS DO LAGO DE FURNAS (ALAGO). Estatuto social da ALAGO. Alfenas, abr. 2008. Disponível em: <http://www.alago.org.br/imagens/file/estatuto.pdf> Acesso em: 28 jan. 2016.

Planos Diretores Participativos. Desafios: inclusão social e desenvolvimento regional. Boletim da Alago, Alfenas, ano. 1, n. 1, p.1, ago. 2006. Disponível em: <http://www.alago.org.br/imagens/file/ Boletim1.pdf>. Acesso em: 11 set. 2015.

. Diagnóstico técnico das condições de saneamento dos municípios da região do lago de Furnas. Alfenas, mar. 2005. Disponível em: <http://www.alago.org.br/imagens/ file/saneamento.pdf > Acesso em: 25 nov. 2016.

BOA ESPERANÇA (Cidade). Prefeitura Municipal de Boa Esperança. O lago. Abr., 2013. Disponível em: <http://www.boaesperanca.mg.gov.br/detalhe-da-materia/info/destinos-mais-procurados/6485>. Acesso em: 26 jul. 2017.

BRASIL. Ministério Público Federal. Procuradoria da República em Minas Gerais. Construção de mais um condomínio de luxo às margens de Furnas destrói Mata Atlântica. Out. 2015. Disponível em: <http:// www.prmg.mpf.mp.br/imprensa/noticias/meio-ambiente/construcao-de-mais-um-condominio-de-luxoas-margens-de-furnas-destroi-mata-atlantica>. Acesso em: 29 jan. 2016.

BRASIL. Decreto n. 41.066, de 28 de fevereiro de 1957. Concede autorização para funcionar como empresa de energia elétrica à Central Elétrica de Furnas S.A.- Furnas. Disponível em: <http://www2.camara.leg.br /legin/fed/decret/1950-1959/decreto-41066-28-fevereiro-1957-379830-publicacaooriginal-1-pe.html>. Acesso em: 26 dez. 2015.

CAMPOLINA, Bernardo. O planejamento regional e urbano no Brasil. Revista Política e Planejamento Regional, Rio de Janeiro, v. 1, n. 2, p. 345-8, jun. 2014. Disponível em: <http://www.revistappr.com.br/ artigos/extra/550dde7471486.pdf>. Acesso em: 25 nov. 2016.

CAPITÓLIO (Cidade). PMSB - Plano municipal de saneamento básico município de Capitólio. Capitólio, MG, 2016. Disponível em:<https://www.capitolio.mg.gov.br/publicos/44_pmsb_capitolio.pdf>. Acesso em: 26 jul. 2016.

CHOAY, F. O urbanismo: utopias e realidades- uma antologia. São Paulo: Perspectiva, 1979.

CONTRIM, John R. A história de Furnas: das origens à fundação da empresa. Rio de Janeiro: Comitê Brasileiro do Conselho Mundial da Energia, 1994.

FRANCO, José. Uma cidade à espera do dilúvio. O Cruzeiro, Rio de Janeiro, v. 32, n. 8, p. 88-91, dez. 1959. Disponível em: <http://memoria.bn.br/docreader/DocReader.aspx?bib=003581\&PagFis=121912>. Acesso em: 29 dez. 2015.

GEDDES, Patrick. Civics: as applied sociology by Sir Patrick Geddes. Londres: University of London, 1904. Disponível em: $<$ http://www.gutenberg.org/catalog/world/readfile?fk_files=1490671\&pageno=2>. Acesso em: 23 ago. 2013.

HALL, Peter. Cidades do amanhã: uma história intelectual do planejamento e do projeto urbanos no século XX. São Paulo: Perspectiva, 2005.

HOWARD, Ebenezer. Cidades: jardins de amanhã. São Paulo: Hubitec, 1996.

LEMOS JÚNIOR, Clésio Barbosa. A implantação da usina hidrelétrica de Furnas e suas repercussões: estudo sobre a territorialização de políticas públicas. 2010. 116f. Dissertação (Mestrado em Geografia) - Universidade Estadual de Campinas (UNICAMP), Campinas, SP, 2010. Disponível em: <http://www.bibliotecadigital.unicamp. br/document/?code=000778319>. Acesso em: 26 dez. 2015.

LOCARNO, Leonardo; BAHIA, Eduardo Trindade; FERREIRA, Wanyr Romero. Estudo da sustentabilidade do desenvolvimento turístico em reservatórios de hidroelétricas. Reuna, Belo Horizonte, v. 13, n. 2, p.11-31, ago. 2008. Disponível em: <http://www.spell.org.br/documentos/ver/5520/estudoda-sustentabilidadedo-desenvolvimento-turistico-em-resevatorios-dehidroeletricas/i/pt-br>. Acesso em: 17 out. 2018. 
MARCONI, Marina de Andrade; LAKATOS, Eva Maria. Técnicas de pesquisa. São Paulo: Atlas, 2012.

MINAS GERAIS. A. J. Gray. Governo do Estado de Minas Gerais. Plano de desenvolvimento do Lago de Furnas. Belo Horizonte: Secretaria da Indústria, Comércio e Turismo do Estado de Minas Gerais, 1975.

ÚLTIMAS NOTÍCIAS. Lago dos milhões: Furnas é alvo de empreendimentos milionários. Formiga, 17 out. 2011. Disponível em: <https://www.ultimasnoticias.inf.br/noticia/lago-dos-milhoes-furnas-e-alvo-deinvestimentos-milionarios/>. Acesso em: 30 nov. 2017.

VIANNA, Mônica Peixoto. O Planejamento Regional Integrado da TVA e sua influência no Brasil: o caso da CESP. In: BROSE, Markus E. A TVA e as Instituições de Desenvolvimento Regional: contribuições para a história das ideias. Santa Cruz do Sul: UNISC, 2015. p. 54-70. Disponível em: <http://www.unisc.br/portal/ upload/com_editora_livro/ebook_06015.pdf>. Acesso em: 10 maio 2016.

VIANNEY, Keuly. Região recebe R\$ 10 milhões de royalties. Folha da Manhã, Passos, p. 3-3. 2 mar. 2008. Disponível em: <http://webcolab.furnas.com.br/Administracao/fonline_Internet2.nsf/Lista-Noticias/ FF92C450823C80C7832574050042EE3D/\$File/Folha_da_Manha-materia.pdf?OpenElement>. Acesso em: 29 nov. 2017.

\section{Sobre os autores:}

Carlos Eduardo Pozzer: Doutorando no Departamento de Recursos Hídricos, Energéticos e Ambientais da Faculdade de Engenharia Civil, Arquitetura e Urbanismo da UNICAMP. Professor do Curso de Arquitetura e Urbanismo da PUC Minas Poços de Caldas. E-mail: pozzer@pucpcaldas.br

André Munhoz de Argollo Ferrão: Doutor em Arquitetura e Urbanismo pela Faculdade de Arquitetura e Urbanismo da Universidade de São Paulo (FAU-USP), Mestre em Engenharia Agrícola pela Faculdade de Engenharia Agrícola (Feagri-Unicamp), Engenheiro Civil, Arquiteto e Urbanista. Professor Livre Docente do Departamento de Recursos Hídricos da Faculdade de Engenharia Civil, Arquitetura e Urbanismo, da Unicamp. E-mail: argollo@fec.unicamp.br 
